\title{
Baseline Survey on Cases of Poisoning and its Outcome in Bangladesh
}

\author{
Md Robed Amin ${ }^{1 *}$, Ariful Basher ${ }^{2}$, Abdus Sattar ${ }^{3}$, Anisul Awal ${ }^{3}$, Mustaque Rahim Sapan $^{4}$, Aniruddha Ghose ${ }^{5}$ \\ and MA Faiz ${ }^{5}$ \\ ${ }^{1}$ Dhaka Medical College, Bangladesh \\ ${ }^{2}$ Mymensing Medical College, Bangladesh \\ ${ }^{3}$ Chittagong Medical College, Bangladesh \\ ${ }^{4}$ Rajshahi Medical College, Bangladesh \\ ${ }^{5}$ Sir Salimullah Medical College, Bangladesh
}

Submission: May 03, 2017; Published: October 12, 2017

*Corresponding author: Dr. Md. Robed Amin, Associate Professor of Medicine, Department of Medicine, Dhaka Medical College, Dhaka, Bangladesh, House no-76, Road no-5, Block-F, Banani, Dhaka, Bangladesh, Email: robedamin@yahoo.com

\section{Introduction}

Poisoning and snake bite are commonly encountered emergency situation in Bangladesh. Pesticide, copper sulphate, kerosene and poisoning by unknown sedative substances for stupefying purpose and with occasional reports of methanol, aluminum phosphide poisoning and puffer fish intoxication are often faced by the different level of Physicians. Chittagong Medical College Hospital alone $>1000$ cases of poisoning and 400 cases of snake bite were reported in one year. One hundred ten cases of death following poisoning were reported from the same hospital [1]. Mortality due to pesticide poisoning has been found to be $14-15 \%$ in developing country comparison to $<1 \%$ in the developed world [2]. The Health Bulletin of the DGHS, 1998 has tabulated the data of the disease profile including poisoning cases from the year 1988 to 1996 on hospital records at the district level and below. It has been observed that the incidence of poisoning has been on increase gradually since 1988 to 1996 except in the year 1990 and 1993 [3].

The number of chemicals used in industry, agriculture and medical profession is rising faster than it was anticipated. Consequently misuse of pesticides, chemicals (toilet cleaner, nail polish, rat killer) drugs (sedatives) has been observed. Highly toxic chemicals are used as fertilizer, pesticides, industrial solvents, food additives, medicines, cosmetics and wide range of other manufacturing procedure. Exposure to chemicals does not affect everyone exactly in the same way. Most of the fatal victims of poisoning are young adults and from poor rural community. Small scale psychiatric analysis of deliberate self poisoning victims could not detect high proportion of major psychiatric illness among the poisoned cases [4]. Easy availability of cheap pesticide within the household could contribute to use them as agent of deliberate self harm.

A large number of poisoning cases remains un-reported due to lack of information and awareness at community level. Unfortunately there is no systematic record keeping system for poisoning and snake bite cases; which is pre-requisite for assessing magnitude of health problem. Therefore, study on baseline survey on cases of poisoning and its outcome [5] has been designed to collect baseline information and assess magnitude of health problem that occurs due to poisoning and snake bite. The study findings will help the health planners to prepare plan of action for proper management of poisoning and snake bite cases.

\section{Methodology}

\section{Selection of study area}

Study area was selected purposively where higher incidence of poisoning cases was reported by government authority. Dhaka Medical College Hospital (DMCH), Chittagong Medical College Hospital (CMCH), Jhenaidha General Hospital, Coxs Bazar General Hospital and 7 primary care level health centers were selected for our survey.

\section{Development of registration format}

The case record form contains demographic information of patients e.g. name and address, age, sex, religion, name of poisonous substance, type of poisoning, outcome of poisoning etc. The common poisonous substances were coded [6]. A fixed code number was used for "others". In this code number we included chlorohexidine solution, harpic, nail polish, drug except 
sedative, naphthalene, dhutura, depilatory, cream, mortein, rat killer, anti-louses, ant-scabies, acid etc. All cases of poisoning including snake bite admitted or attended the selected hospitals during the study period were recorded in a poisoning register form. The outcome of the cases was also recorded. We used Internal Medicine, Pediatrics, Forensic Medicine and Emergency room of $\mathrm{DMCH}, \mathrm{CMCH}$ \& other hospitals for registration of poisoning cases.

\section{Diagnosis of patients}

Diagnosis was done by history taking and clinical examination of patients by trained doctors. In Many cases the poisoned person or the attendants used to bring bottle/boxes of toxic substances they abused. In that case we cross-checked the contents of drug container for confirmation of poisoned substance. In some cases we collected information from the note of poisoned person. All these were done within few minutes to avoid casualties [7]. In case of snake bite, sign of bite mark was observed. The identification of snake through description and photograph was also supplemented. Food intoxication was reported by patients or attendants regarding type of food they taken. Sometimes patients or attendants used to bring the killed snake or food samples with themselves.

\section{Management of poisoning cases}

Management was dependent on the stage of poisoning. We provided supportive care to most of the patients with minor poisoning state i.e. if the patient was found alert and with stable blood circulation. However, additional therapy including maintaining adequate respiration and circulation was the first priority in all cases [8-10]. The patient were nursed in the lateral position with the lower leg straight and the upper leg flexed; in this position the risk of aspiration was reduced. A clear passage for air was ensured by the removal of any obstructing object, vomit or dentures, and by backward pressure on the mandible. Meticulous supportive care including the treatment of seizures, collapse, respiratory and cardiovascular complication was ensured in case of seriously poisoned patients.

\section{Data entry and analysis}

One person was recruited to enter data in the computer. Windows SPSS-16 (manufactured by Chicago illionois) program was used for data analysis. Data entering clerk entered data from the register in a SPSS program at the end of the study. Data was analyzed and the report was prepared. Data were presented in percentage and mean. P value $<0.05$ was considered significant. As the case record form contained recorded data from hospitalized cases, no individual information was disclosed.

\section{Results}

During the study period total 31,329 cases were admitted in selected health facilities among them 4,553 (14.5\%) were due to poisoning. Study showed that $29.0 \%$ poisoning occurs due to anti cholinergic pesticide, $37.1 \%$ by sedative, $9.5 \%$ following snake bite, $3.0 \%$ by Kerosene, and rest $22.5 \%$ were due to other substances like methanol, copper-sulphate, puffer fish, harpic, drugs except sedative, naphthalene, nail polish, Dhutura, Chlorine gas, depilatory cream, mortein, rat killer, anti-louse, anti-scabies, inorganic acid, etc [11-14].

The agents used for poisoning were organophosphorus pesticide $25.2 \%$, carbamate pesticide $0.7 \%$, other pesticide $2.5 \%$ (presumably), benzodiazepine $16.1 \%$, other sedatives $20.7 \%$, snake bite $9.5 \%$, kerosene $3.1 \%$, methanol $200.4 \%$, Puffer fish (Potka fish) poisoning .01\%. Total $21.6 \%$ cases of poisoning was categorized under other causes i.e. chlorohexidine solution, Harpic, Nail polish, drugs except sedatives, Naphthalene, Dhutura, Chlorine gas, depilatory, cream, mortein, rat killer, antilouse, anti-scabies, acid, etc, were registered in the hospital.

Poisoning due to unknown sedative was mostly registered in Dhaka Medical College Hospital and victims were mostly commuters. Total 1675 sedative poisoning cases were registered; among them 1492 (above 89\%) cases were admitted in DMCH [15]. Whereas, snake bites cases were more in Chittagong Medical College Hospital. Among 434 snake bite cases 303 (above 69\%) cases were registered in $\mathrm{CMCH}$. Maximum number of Organo-phosphate poisoning was registered in Jhenaidaha General Hospital. Total number of poisoning cases in Jhenaidaha general hospital is above 4 times higher than that of Coxsbazar General Hospital.

Total $3003(66 \%)$ of poisoning cases were male and 1550 $(34 \%)$ were female. The age distribution of the poisoning cases shows that $491(10.8 \%)$ cases were up to the age of 12 years, $1144(25.1 \%)$ cases between $13-20$ years, $1576(34.6 \%)$ cases between $21-30$ years, and 785(17.2\%) between 31-40 years. The rest were above 41 years [16].

About 20\% of poisoned cases are categorized under the headline others i.e. chlorohexidine solution, Harpic, Nail polish, drugs except sedatives, Naphthalene, Dhutura, Chlorine gas, depilatory, cream, Mosquito's repellents, rat killer, anti-louse, anti-scabies, acid, etc.

Table 1 reveals that a substantial proportion (45.9\%) of cases were due to deliberate self harm, $32.4 \%$ due to stupefying, $20.3 \%$ are accidental poisoning and $1.4 \%$ due to homicidal purpose. Table 1 further shows that homicidal cases is 3 times higher among female than male, self harm type of poisoning is also higher among female than male, where as accidental poisoning is above 2 times higher and stupefying is about 10 times higher among male than female. Considering incidence of poisoning among male female i.e. $66 \%$ and $34 \%$ respectively; homicidal poisoning is 6 times higher and self harm poisoning is above 2 times higher among females, on the other hand stupefying is about 5 times higher and the accidental poisoning is slightly higher among male population. 
Table 1: Distribution of patients by poisonous type, gender and religion.

\begin{tabular}{|c|c|c|c|c|c|c|c|c|c|c|c|}
\hline \multirow{3}{*}{ Poison Type } & \multicolumn{8}{|c|}{ Religion and Gender of Patient } & \multicolumn{2}{|c|}{ Total } & \multirow{3}{*}{ Total } \\
\hline & \multicolumn{2}{|c|}{ Islam } & \multicolumn{2}{|c|}{ Hindu } & \multicolumn{2}{|c|}{ Buddhist } & \multicolumn{2}{|c|}{ Christian } & \multirow[b]{2}{*}{ Male } & \multirow[b]{2}{*}{ Female } & \\
\hline & Male & Female & Male & Female & Male & Female & Male & Female & & & \\
\hline Self harm & 878 & 998 & 86 & 104 & 9 & 5 & 4 & 6 & $\begin{array}{c}977 \\
21.6 \%\end{array}$ & $\begin{array}{c}1113 \\
24.5 \%\end{array}$ & $\begin{array}{r}2090 \\
45.9 \%\end{array}$ \\
\hline Homicidal & 15 & 41 & 2 & 4 & 1 & 0 & 0 & 0 & $\begin{array}{c}18 \\
0.3 \%\end{array}$ & $\begin{array}{c}45 \\
1.0 \%\end{array}$ & $\begin{array}{c}63 \\
1.4 \%\end{array}$ \\
\hline Accidental & 596 & 228 & 63 & 25 & 6 & 6 & 1 & 0 & $\begin{array}{c}666 \\
14.6 \%\end{array}$ & $\begin{array}{c}259 \\
5.7 \%\end{array}$ & $\begin{array}{c}925 \\
20.3 \%\end{array}$ \\
\hline Stupefying, travel & 1264 & 127 & 72 & 6 & 5 & 0 & 1 & 0 & $\begin{array}{c}1342 \\
29.4 \%\end{array}$ & $\begin{array}{c}133 \\
2.9 \%\end{array}$ & $\begin{array}{r}1475 \\
32.4 \%\end{array}$ \\
\hline Total & $\begin{array}{c}2753 \\
60.5 \%\end{array}$ & $\begin{array}{c}1394 \\
30.6 \%\end{array}$ & $\begin{array}{c}223 \\
4.9 \%\end{array}$ & $\begin{array}{l}139 \\
3.0 \%\end{array}$ & $\begin{array}{c}21 \\
0.5 \%\end{array}$ & $\begin{array}{c}11 \\
0.2 \%\end{array}$ & $\begin{array}{c}6 \\
0.1 \%\end{array}$ & $\begin{array}{c}6 \\
0.1 \%\end{array}$ & $\begin{array}{l}3003 \\
66 \%\end{array}$ & $\begin{array}{l}1550 \\
34 \%\end{array}$ & $\begin{array}{c}4553 \\
100 \%\end{array}$ \\
\hline
\end{tabular}

About $4.1 \%$ of total poisoned cases died, among them $3.8 \%$ belongs to self harm group and $0.2 \%$ belongs to accidental cause. survived cases 246 i.e. 5.4\% of total survived cases left the Four patients $(0.08 \%)$ died from stupefying cause of poisoning hospital by their own risk.

Table 2: Distribution of patients according to poisoned substance and outcome.

\begin{tabular}{|c|c|c|c|c|c|c|c|c|c|c|c|c|}
\hline \multirow{2}{*}{$\begin{array}{l}\text { Outcome of } \\
\text { Poisoning }\end{array}$} & \multicolumn{3}{|c|}{ Pesticide } & \multicolumn{2}{|l|}{ Sedative } & \multirow{2}{*}{ Kerosene } & \multirow{2}{*}{$\begin{array}{c}\text { Snake } \\
\text { bite }\end{array}$} & \multirow{2}{*}{$\begin{array}{l}\text { Cu- } \\
\text { Sulph }\end{array}$} & \multirow{2}{*}{ Methanol } & \multirow{2}{*}{$\begin{array}{l}\text { Potka } \\
\text { fish }\end{array}$} & \multirow{2}{*}{ Others } & \multirow{2}{*}{ Total } \\
\hline & OP & Carmate & Other & Benzodiazepine & Other & & & & & & & \\
\hline Survived & 1010 & 30 & 121 & 736 & 950 & 136 & 433 & 7 & 17 & 1 & 928 & $\begin{array}{r}4369 \\
95.9 \%\end{array}$ \\
\hline \multirow[t]{2}{*}{ Death } & 158 & 3 & 2 & 1 & 4 & 3 & 1 & 00 & 3 & 00 & 9 & $\begin{array}{c}184 \\
4.1 \%\end{array}$ \\
\hline & \multicolumn{3}{|c|}{$163(88.6 \%)$} & \multicolumn{2}{|l|}{$5(2.7 \%)$} & $1.6 \%$ & $0.5 \%$ & 00 & $1.6 \%$ & \multicolumn{2}{|c|}{$4.9 \%$} & $100 \%$ \\
\hline \multirow[t]{2}{*}{ Total } & 1168 & 33 & 123 & 737 & 954 & 139 & 434 & 7 & 20 & 1 & 937 & 4553 \\
\hline & \multicolumn{3}{|c|}{$1324(29.0 \%)$} & $1691(37.1 \%)$ & \multicolumn{2}{|c|}{$3.0 \%$} & $9.5 \%$ & $0.15 \%$ & $0.43 \%$ & \multicolumn{2}{|c|}{$20.6 \%$} & $100 \%$ \\
\hline
\end{tabular}

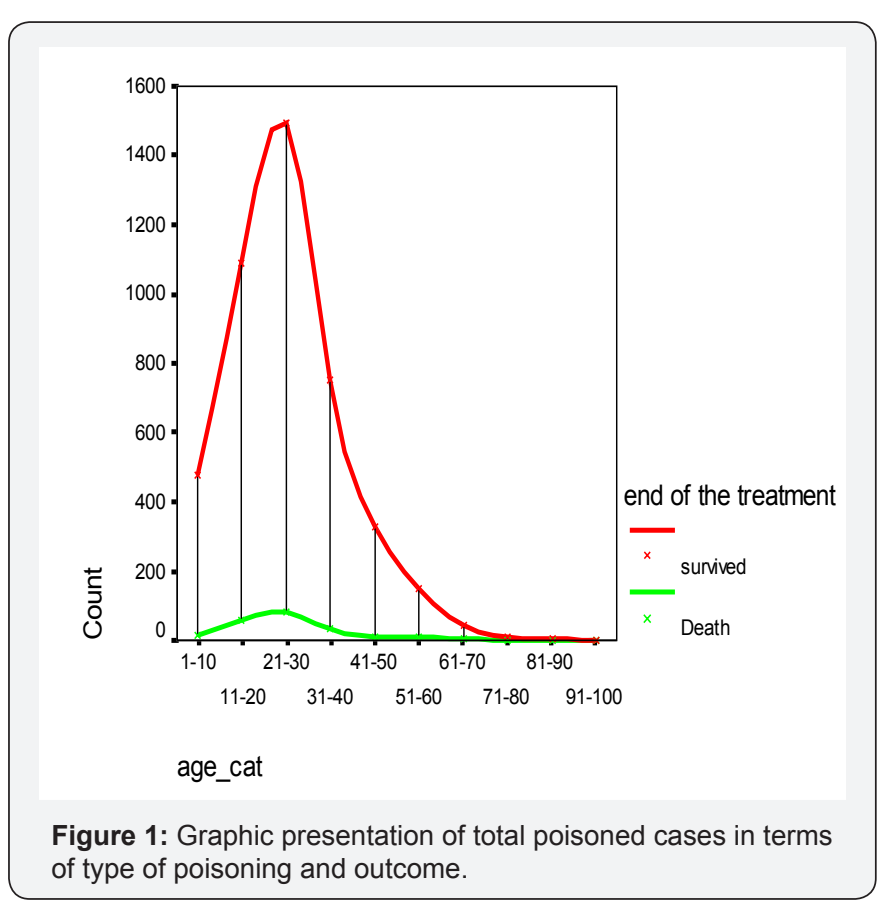

The study demonstrates that the highest number of deaths occur between the age group 21-30 years. The Figure 1 further shows that mortality is proportional to incidence poisoning at different age groups. Table 2 shows that $88 \%$ of total death causes due to pesticide poisoning although about $30 \%$ of total poisoning was caused duet to pesticide. The table further shows that the $37 \%$ poisoning caused by sedative intake while only $2.7 \%$ of total deaths occurred from this group of poisoning. Methanol poisoning contributed $0.43 \%$ of total poisoning cases while it causes $1.6 \%$ of total death [18]. Other causes of poisoning were registered as chlorohexidine solution, Harpic, Nail polish, drugs except sedatives, Naphthalene, etc. From this group about $5 \%$ of total death occurred. Three cases of kerosene poisoning, and 1 case of snake bite died after hospital admission.

Considering the case fatality rate it was found that highest percent $(15 \%)$ of fatal cases were registered among methanol poisoning group. It followed by pesticide poisoning (13\%) and kerosene poisoning (2.1\%). The table further reveals that highest number of poisoning happened due to sedative intake while lowest case fatality rate was found in this group of poisoning. 
Table 3: Distribution of registered patients according to place and name of pesticides.

\begin{tabular}{|c|c|c|c|c|c|c|c|c|c|c|c|c|}
\hline \multirow{3}{*}{$\begin{array}{l}\text { Place of } \\
\text { Case }\end{array}$} & \multicolumn{11}{|c|}{ Name of Pesticide } & \multirow{3}{*}{ Total } \\
\hline & \multicolumn{3}{|c|}{ Pesticide } & \multicolumn{2}{|c|}{ Sedatives } & \multirow[b]{2}{*}{ Kerosine } & \multirow[b]{2}{*}{$\begin{array}{l}\text { Snake } \\
\text { bite }\end{array}$} & \multirow{2}{*}{$\begin{array}{c}\text { Cu- } \\
\text { Sul } \\
\text { phate }\end{array}$} & \multirow[b]{2}{*}{ Methanol } & \multirow[b]{2}{*}{$\begin{array}{c}\text { Potka } \\
\text { fish }\end{array}$} & \multirow[b]{2}{*}{ Others } & \\
\hline & $\mathbf{O P}$ & Carmate & Others & Benzodiazepine & $\begin{array}{c}\text { Other } \\
\text { sedative }\end{array}$ & & & & & & & \\
\hline $\mathrm{DMCH}$ & 279 & 23 & 27 & 601 & 897 & 73 & 102 & 5 & 12 & 1 & 298 & 2318 \\
\hline $\mathrm{CMCH}$ & 299 & 7 & 81 & 119 & 34 & 38 & 303 & 1 & 3 & 0 & 505 & 1390 \\
\hline $\begin{array}{c}\text { Coxsbazar } \\
\text { General } \\
\text { Hospital }\end{array}$ & 90 & 0 & 4 & 4 & 1 & 7 & 0 & 0 & 0 & 0 & 13 & 119 \\
\hline $\begin{array}{c}\text { Hathazari } \\
\text { UHC }\end{array}$ & 26 & 0 & 1 & 3 & 5 & 1 & 16 & 0 & 0 & 0 & 74 & 126 \\
\hline $\begin{array}{l}\text { Jenaida } \\
\text { General } \\
\text { Hospital }\end{array}$ & 445 & 3 & 6 & 8 & 17 & 13 & 1 & 1 & 4 & 0 & 39 & 537 \\
\hline $\begin{array}{l}\text { Sitakund } \\
\text { UHC }\end{array}$ & 29 & 0 & 4 & 2 & 0 & 7 & 12 & 0 & 1 & 0 & 8 & 63 \\
\hline \multirow[t]{2}{*}{ Total } & 1168 & 33 & 123 & 737 & 954 & 139 & 434 & 7 & 20 & 1 & 937 & 4553 \\
\hline & \multicolumn{3}{|c|}{$1324(29.0 \%)$} & \multicolumn{2}{|c|}{$1691(37.1 \%)$} & $3.00 \%$ & $9.50 \%$ & $0.15 \%$ & $0.40 \%$ & \multicolumn{2}{|c|}{$20.60 \%$} & $100 \%$ \\
\hline
\end{tabular}

The causes of death in most of the cases of pesticide poisoning were due to respiratory failure or respiratory involvement requiring assisted ventilation. At times assisted mechanical ventilation could not be provided due to non-availability of free ventilators in the study hospitals. The poison type is more or less homogenously distributed throughout study area. Although Table 3 shows that ingestion a particular toxic substance varied from place to place.

\section{Discussion}

A prospective study conducted in Dhaka Medical College Hospital in 1993 revealed that $2.6 \%$ of total admitted patients are poisoning cases [5]. Poisoning profiles from district and upazilla level hospitals shows gradual increasing trends of the poisoning cases (DGHS 1998). Abdul M.B. states in his report on retrospective study findings of 5 tertiary level care hospitals that above $2.6 \%$ of total admitted cases belongs to poisoning group. Our study finding from selected hospital reveals that $14.5 \%$ of total admitted patients are poisoning cases. An explanation of this high percentage of poisoning might be that we purposively selected poisoned prone areas for our study. The trained doctors paid special attention for registration of poisoned cases.

A nationwide survey report of 13 government medical college hospitals states that male is more vulnerable (Male: Female $=59$ : 41 ) to poisoning [6]. Another study in 7 different health facilities reveals that male female distributions of poisoning cases were unequal in different hospitals of urban and rural areas of Bangladesh. In Munshiganj Hospital the male female ratio was $2: 1$ while in Jhenaidaha hospital the ratio was $1: 2$. In an average the ratio between male and female of 7 different health facilities was 1.44:1.24. Our study findings do not coincide with study reports of 7 different hospitals. But it is more closure to nationwide survey report of 13 different hospitals.

This study reveals that above $28 \%$ of total poisoning cases occurs by pesticides. Retrospective poisoning study of selected hospital in Dhaka division shows that the most common cause of poisoning is organophosphorus compounds. Similar finding was reported from retrospective study of government hospitals in Chittagong (Begum J.A.), Khulna (Azhar M.A. 1992, Halim M.A. 1991, Ahsan HAMN et. al. 1989) and Rajshahi divisions (Nag M.N. Et. al.1998, Azhar M.A. 1994); while 'Dhutura' was the most common poisoning cause in Noakhali General Hospital (Hoque M.F.1986) [7-12]. Easy availability of pesticides has become commonly used for intentional self-poisoning (Jeyaratnam J). Thomas et al. 2000 [14], states that pesticide poisoning cause most self poisoning death in southern and central India. Gautami et al. states that pesticide use is high in Andhra Pradesh for agriculture purpose and this province belongs to one of the highest reported rates of pesticide poisoning in India [15]. Use of pesticide in agriculture might be the cause of easy access of community people to pesticide. On the other hand our study found sedative as the most common poisoning cause. The current UN Food \& Agricultural Organization (FAO) guidelines suggest that all class 1 organ-phosphorus compounds should be withdrawn from the agricultural practice. Robert et al. 2003 states that bans on more toxic pesticide and endosulfan might have pivotal role reducing mortality from pesticide poisoning in some Sri Lankan hospital below 15\% from 22\% [16]. Eddlestone \& Konradsen state that targeted restriction of the most commonly fetal pesticides may bring down the number of deaths in Warangal $[17,18]$. Bangladesh government has signed the Stockholm convention on Persistant Organic Pollutant (POP) on 
23 May 2001. Uses of pesticides have been restricted since that time. As a result availability of pesticide has become difficult. It might be the reason of reduced pesticide poisoning incidents in our study. Faiz MA states in his report that, pesticides use begun in the then East Pakistan in 1956. About 86 ingredients are registered in Bangladesh representing more than 200 products with plant protecting wing. Fifteen ingredients have been banned in Bangladesh and two items are restricted in the country.

This study reveals that about $89 \%$ of total death occurs due to pesticide poisoning although only $29 \%$ poisoning cause by it. A retrospective study conducted in Mahatma Ghandi Hospital (1997-2002) states that $22 \%$ of total OP poisoned cases died. This study indicates high mortality rate among pesticide poisoning than our study in selected hospital of Bangladesh (12.23\%). This might be due to improvement of management in medical field during last 8 years. Improved communication might be another factor that contributes to quick transport of patients to hospitals.

The highest percentage of death occurred due to organphosphorus poisoning and respiratory failure or lack of respiratory related assisted ventilation support was the cause of death. M Eddleston et al. states that early transfer of ill patients to an ICU for close observation was usually not possible, resulting in death. The study further reveals that $24 \%$ of OP poisoning required intubations and ventilation support during their hospital admission and $49 \%$ of intubated patients survived. WHO report states that artificial ventilation is very effective in life saving for severe pesticide poisoning and neurotoxic snake bite. Our study noticed that maximum death occurred due to non-availability of free ventilators i.e. we could not provide ventilation support to the patients at due time.

Total admitted poisoned cases in DMCH is two times higher than $\mathrm{CMCH}$. Whereas snake bite cases in Chittagong Medical College Hospital is almost three times higher than that of Dhaka Medical College Hospital. Geographical location of CMCH might the reason of this extremely high incidence of snake bite cases in $\mathrm{CMCH}$. Similarly high incidence of snake bite was also observed in primary level care hospital. High incidence of snake bite among male might be due to nature of their job.

Maximum cases of pesticide poisoning were reported in Jhenaidaha general Hospital. Among 537 registered cases in this hospital 444 were due to pesticide. Jhenaidaha is a district of intensive agriculture production. Therefore pesticide use is high. This might be a reason of highest reported rates of pesticide poisoning in this district. Gautami et al. states correlation of pesticide poisoning and agro rich area in India. Jenaidha district of Bangladesh is well known for high incidence of suicidal cases.

Our study reveals that highest percentage of sedative poisoning was registered in $\mathrm{DMCH}$. In the resent years increase in incidence of poisoning by drugs is due to easy availability of sedatives in our country. Faiz MA further states that sedative are common among the affluent people. We assume that easy accessibility of sedatives in the pharmacies of town and cities might have contribution to high incidence of sedative poisoning. It may be mentioned that in Bangladesh people may collect sedatives even without doctor's prescription. Diazepam and barbiturate derivates are available in almost all the pharmacies of Bangladesh even at remote part of the country.

Comparatively more female takes pesticides than the male. On the other hand more male takes sedative than female. This appears due to easy accessibility of pesticides at home level. The usual story of the victim is that for destroying pests and insects some chemicals were brought. Part of the pesticides was used and remainder was preserved in a readily accessible place. On the other hand male have easy access to sedative for collecting from nearby pharmacy. Some monetary involvement is required to buy sedatives. The females have no money to buy sedatives from pharmacy. Incidence of methanol intoxication is 4 times higher among male than female. In our society male are more prone to alcohol consume. This might have contribution of high incidence of methanol intoxication among male.

Above $10 \%$ of poisoned cases are between 1-12 years age. In this age the children express grievance by crying or expressing anger to parents. This age is too early to take emotional decision for self-harm or harm to others. In rural Bangladesh one family has several children and often mother has no time to pay proper attention to her children. Children roam hither and thither without any attention and put in mouth whatever he finds within the reach. Thus the children come in contact with toxic substances like pesticides, kerosene, harpic, naphthalene, nail polish, drugs, etc; those are kept at home without proper attention. This might be the cause of high accidental incidence of poisoning among the children. Although self-harm type of poisoning was the highest percentage in our study; particularly in the age group of 1-12 years accidental case was the highest. Further analysis reveals that accidental poisoning was about 9 times higher in the age group 1-12 years than self harm type of poisoning.

13-20 years is a dangerous stage for children. In this age the children are emotional and take decision without thinking on its consequences. The highest number of self-harm poisoning occurred in this age group. An emotional stage of life prevails up to the age 30 years as a result in addition to self harm do harm to others increases during 21-30 years age group. The adults of this age group are mobile and travel to cities for search of job or earning source. That might be the reason of increased stupefying in this age group. Similarly there is increasing tendency of stupefying poisoning among the age group 31 and above.

Homicidal poisoning is only $1.3 \%$ of total registered poisoning cases. In age group 21-30 years homicidal is in the highest position. In this age people come in contact with other people outside home. His friend circle increases and 
interpersonal conflict may happen. To wean the conflict a man might have poisoned to his friend or enemy homicidally. This is reflected in our study finding that homicidal poisoning incidence increases in ages between 13-20 years and become highest in the age group 21-30 years and continues as the 2 nd common cause among the age group 41 years and above. The study further reveals that homicidal cases are almost 6 times higher among female than male. This finding coincides with often reported poisoning, acid burn or physical torture to newly married girls by husband or in-laws family members for dowry.

Stupefying cases is about 6 times higher than self-harm among the age group 31-50 years. These age groups of people travel frequently. The criminals stupify them on the way to achieve their ill motive e.g. robbing, sexual abuse of girls, trafficking of children, etc. There are study findings that stupefying cases increases just before 'Eid or Puja, festival. Faiz MA conducted a study on poisoning cases in 2003 in a special period over 7 days. The study found that 28 poisoning cases $(9.6 \%$ of total admitted cases) were admitted in the hospital among them 18 were due to travel related i.e. stupefying poisoning.

Poisoning is one of the commonest causes of hospital admission in Bangladesh. Creation of evidence by recording cases of poisoning and snake bite needs to be done for identifying the extent of problem. Provision for necessary supply of logistics at appropriate level of care is required. In depth studies related to various aspects of poisoning by different agents could be conducted for further improvement of management and prevention.

\section{References}

1. Bari MA, Faiz MA (2003) A Programme to establish a Poison Information Centre in Bangladesh, Final Report.

2. Srinivas Rao CH, Venkateswarlu V, Surender T, Michael Eddleston, Buckley NA (2005) Buckley: Pesticide poisoning in south India: opportunities for prevention and improved medical management. Trop Med Int Health 10(6): 581-588.

3. Alam MS, Haq SM, Faiz MA, Hossain A (1999) Assessment of Psychiatric condition in deliberate self-harm by OPC poisoning. Bangladesh J Psychiatry 13(1): 21-30.

4. Rahman MM (1994) Clinical pattern of acute poisoning in medical units of DMCH. JDMC 3(1): 1-5.

5. Faiz MA (2002) Nationwide Survey of pattern of Poisoning in Bangladesh.

6. Begum JA (1998) Study of poisoning in four hospitals in Bangladesh BMJ 2(89): 60-64.

7. Azhar MA (1992) Poisoning cases in district hospital in Bangladesh. JOPSOM 11(2): 69-72.

8. Halim MA (1991) A study on reason of poisoning in a selected thana health complex in Jenaidha district. Dissertation, NIPSOM.

9. Ahsan HAMN (1989) Poisoning-An analysis of the Khulna General Hospital Cases, BMJ, Khulna 22(2): 1-9.

10. Nag MN (1998) A study on poisoning cases, our experiences in Rangpur Medical College Hospital NMJ 7(1): 1-4.

11. Azhar MA (1994) Poisoning pattern in medical outdoor- is it changing? Taj (Raj) 7(2).

12. Hoque MF (1986) Incidence and clinical pattern of poisoning in district hospital. BMJ 15 (1\&2): 13-17.

13. Jeyaratnam J (1990) Acute pesticide poisoning: A major global health problem. World Health statistic quarterly 43(3): 139-144.

14. Gautami S, Sudershan RV, Bhat RV, Suhasini G, Bharati M, et al. (2001) Chemical poisoning in three Telengana districts of Andhra Pradesh. Forensic Sci Int 122(2-3): 167-171.

15. Roberts DM, Karunarathna A, Buckley NA, Manuweera G, Sheriff MH, et al. (2003) Influence of pesticide regulation on acute poisoning deaths in Sri-Lanka. Bulletin of the World Health Organization 81(11): 789798.

16. Eddleston M, Buckley NA, Checketts H, Senarathna L, Mohamed F, et al. (2004) Speed of initial atropinisation in significant organophosphorus pesticide poisoning - a comparison of recommended regimens. J Toxicol Clin Toxicol 42(6): 865-875.

17. Konradsen F, van der Hoek W, Cole DC, Hutchinson G, Daisley H, et al. (2003) Reducing acute poisoning in developing countries-options for restricting the availability of pesticides. Toxicology 192(2-3): 249-261.

18. Eddleston M, Karalliedde I, Buckley N, Fernando R, Hutchinson G, et al. (2002) Pesticide poisoning in the developing world-a minimum pesticides list. Lancer 360(9340): 1163-1167.

\section{Your next submission with Juniper Publishers will reach you the below assets}

- Quality Editorial service

- Swift Peer Review

- Reprints availability

- E-prints Service

- Manuscript Podcast for convenient understanding

- Global attainment for your research

- Manuscript accessibility in different formats

( Pdf, E-pub, Full Text, Audio)

- Unceasing customer service

Track the below URL for one-step submission https://juniperpublishers.com/online-submission.php 